\title{
Chronic Subdural Hygroma in Battered Baby.
}

\author{
Bhaisare $\mathrm{K}^{1{ }^{*}}$, Holikar S. ${ }^{2}$ \\ DOI: https://doi.org/10.17511/ijpr.2021.i04.05 \\ 1* Kiran Bhaisare, Associate Professor, Department of Paediatrics, Vilasrao Deshmukh Institute of Medical science, Latur, Maharashtra, \\ India. \\ 2 Sunil Holikar, Associate Professor, Department of Paediatrics, Vilasrao Deshmukh Institute of Medical science, Latur, Maharashtra, India.
}

The battered baby syndrome is a condition in which a child is seriously physically abused by the caregiver or parents. The World Health Organization (WHO) estimates 40 million children are subjected to abuse and neglect around the world. Most of the industrialized countries have their reporting and surveillance system and data on child battery but in developing countries including India, there is a lack of data regarding the extent of child battering that takes place within the households or institutions. India published a report on one of the largest surveys done on child abuse and found that two out of every three children were physically abused and $88.6 \%$ of them suffered at the hands of their parents. Unfortunately, the methodology restricted the study to only older children who could give a history of abuse. Therefore, the magnitude of the problem given only highlights among children above the age of 5 years. [1]. we are reporting a case of an Infant with Febrile encephalopathy, detailed examination and investigation found out a case of chronic Subdural Hygroma with classical neuroimaging features of Abusive trauma. We have done a multidisciplinary approach with a Neurosurgeon, a social worker who treated the child with burr hole surgery for subdural hygroma \& the child recovered with consciousness. This case is Special because a 5-month Male infant was subjected to abuse due to a psychological problem in a Family Member, suspicion was lacking as males are unlikely to undergo gender-biased in India and Early age of presentation.

Keywords: Abusive Head trauma, Febrile encephalopathy, Child Abuse, Multiple Fractures

Corresponding Author

Kiran Bhaisare, Associate Professor, Department of Paediatrics, Vilasrao Deshmukh Institute of Medical science, Latur, Maharashtra, India. Email: drkiranbhaisare@gmail.com
How to Cite this Article

To Browse

Kiran Bhaisare, Sunil Holikar, Chronic Subdural Hygroma in Battered Baby.. Pediatric Rev Int J Pediatr Res. 2021;8(4):196-200.

Available From

https://pediatrics.medresearch.in/index.php/ijpr/arti cle/view/690

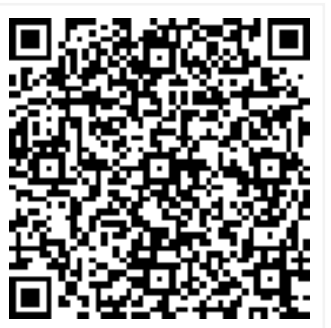

\begin{tabular}{|c|c|c|c|c|}
\hline \multicolumn{2}{|c|}{$\begin{array}{c}\text { Manuscript Received } \\
2021-07-16\end{array}$} & $\begin{array}{c}\text { Review Round } 1 \\
2021-07-29\end{array}$ & $\begin{array}{c}\text { Review Round } 2 \\
2021-08-06\end{array}$ & $\begin{array}{c}\text { Review Round } 3 \\
2021-08-14\end{array}$ \\
\hline & $\begin{array}{c}\text { Conflict of Interest } \\
\text { No }\end{array}$ & $\begin{array}{c}\text { Funding } \\
\mathrm{Nil}\end{array}$ & $\begin{array}{c}\text { Ethical Approval } \\
\text { Yes }\end{array}$ & $\underset{7 \%}{\text { Plagiarism X-checker }}$ \\
\hline OPEN & (c) 2021 by & $\begin{array}{l}\text { e, Sunil Holikar and } \\
\text { ss article licensed } \\
\text { https://creativeco }\end{array}$ & $\begin{array}{l}\text { Siddharth Health R } \\
\text { tive Commons Attrib } \\
\text { licenses/by/4.0/ unp }\end{array}$ & $\begin{array}{l}\text { cial Welfare Society. This i } \\
\text { national License } \\
.0] \text {. }\end{array}$ \\
\hline
\end{tabular}

Accepted 2021-08-21

Note 


\section{Introduction}

Child abuse is referred to a behavior in which a child is exposed to different physical and sexual abuses, neglect or emotional misconduct. The clinical condition of seriously physically child abused by parents or caregivers is called Battered Baby syndrome [2,3]. It is also known as child abuse syndrome, shaken baby syndrome, Caffey's syndrome, maltreatment syndrome in children. Psychiatric factors in the preparator are probably of prime importance in the pathogenesis of the disorder [4].

In the paediatric population, the chronic subdural fluid collection is a group of related conditions termed extracerebral (or extra-axial) fluid collection. Chronic subdural fluid collection can present as chronic subdural hematoma or subdural effusion. The terms subdural hygroma, subdural hygroma, chronic subdural hematoma and benign extracerebral fluid collection etc have been used very loosely in past to describe the same entity. [5].

The most common cause of subdural fluid collection in children is meningitis in about $42 \%$ of cases. The second common cause is a head injury in about $24 \%$ of cases. Frequently, the traumatic episode passes without medical attention. Traumatic causes may be either accidental or nonaccidental (i.e., child abuse). Nonaccidental trauma is the most common cause of subdural hematoma in children less than 2 years of age. [5].

In this article, we are Reporting a case of an infant with Febrile encephalopathy because of chronic subdural hematoma of nonaccidental origin or Infection which turned out to be a case of Child abuse after detailed evaluation.

\section{Case history}

A 5-month-old male child, born of the nonconsanguineous marriage, 2nd by order presented with $\mathrm{C} / \mathrm{o}$ fever, multiple episodes of vomiting and Convulsions in form abnormal tonic posturing of upper and lower limbs with uprolling of eyeballs 3-4 episodes. Each episode lasted for 15 minutes. The patient was very irritable in between the episodes. The patient had $3 y r$ old younger brother with normal development. On detailed clinical examination child was irritable, febrile, HR140/minute, RR 38/minute, spo2 $98 \%$ off O2, pulse palpable with good volume, BP $80 / 60 \mathrm{mmhg}$.
Pupils were dilated bilaterally reactive, fontanelle open and tensed, signs of raised intracranial tension present. Head circumference was normal. signs of moderate malnutrition were present. Another systemic examination was within normal limits. No Focal neurological deficit or cranial nerve palsy. Signs of Meningeal irritation were absent. No signs of trauma or bruises all over the body. the patient was Stabilized and measures to reduced raised Intracranial tension and antiepileptic drugs started initially, no further episodes of convulsion after starting treatment, but the irritability and pupillary dilatation were persisted.

Blood investigations like CBC, CRP, Rapid antigen test for Covid 19, LFT, RFT, BSL and electrolytes were normal, $25(\mathrm{OH})$ VIT D level $8.30 \mathrm{ng} / \mathrm{ml}$ on the lower side. Alkpo4 was normal. Fundus and CSF examination was within normal limits. The patient was treated as a case of Acute febrile encephalopathy. MRI brain has done, suggestive of chronic subdural hygroma along with bilateral cerebral and cerebellar convexities.

\section{Radiological examination revealed:}

01 . Fracture at the distal shaft of Right radius with adjacent callus formation.

02. Metaphyseal fracture is seen in the right distal femur.

03. Old healed fractures are seen in the left 2nd, 3rd, 4th metatarsals.

Based on the clinical and radiological background, we kept two differential diagnoses Child abuse and though rare but Genetic condition Osteogenesis Imperfect. OI is ruled out as there was the absence of family history, Blue sclera, Ligament laxity and Hypotonia on CNS examination and Typical location of Diaphyseal fractures. Bone mineral density was normal.

We concluded that this is a case of Battered Baby Syndrome with bilateral subdural hygroma, grade 2 malnutrition with Vitamin D deficiency.

\section{The points which lead to the diagnosis are}

01 . Multiple fractures in different stages of healing.

02. Chronic subdural hygroma.

03. Poor nutritional status and hygiene.

04. Delay in seeking medical attention.

05. The other sibling was alright.

06. Got History of abuse from grandmother. 
Burr hole with drain insertion done in the Right frontoparietal region for subdural hygroma, the patient was improved on treatment.

The case was handled with a multidisciplinary approach with a Team of Pediatrician, Radiologists, neurosurgeons, psychologist, Nutritionists and Social workers. The effort is to prevent retraumatization of the child and ensure that the victim has access to proper medical, legal and psychological Treatment.
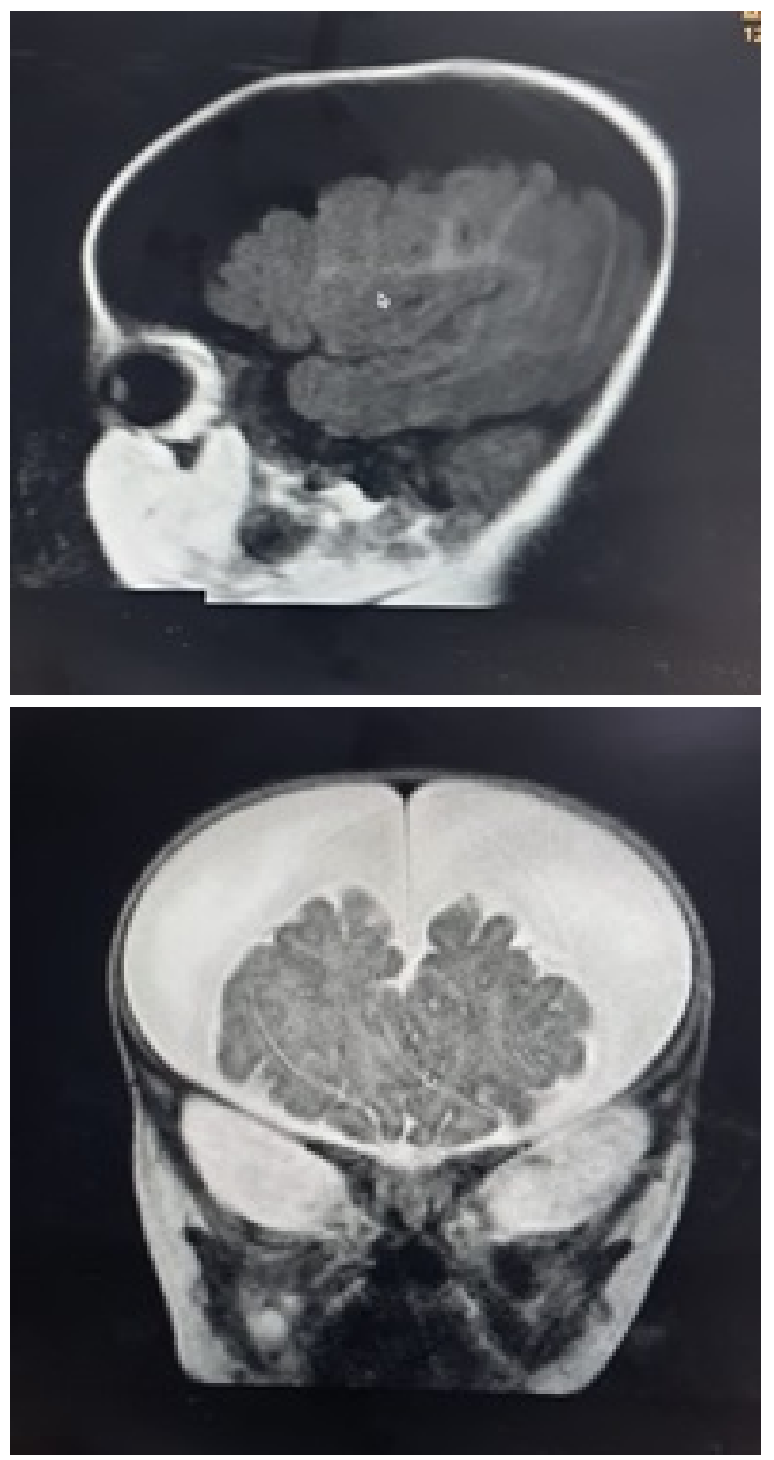

Figure 1. MRI imaging s/o bilateral large CSF intensity subdural collection without diffusion restriction.

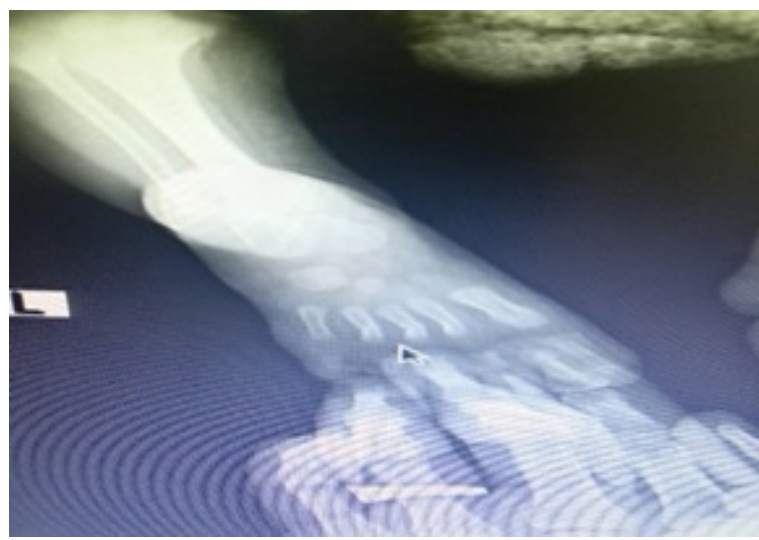

Figure 2. Old healed fractures of 2nd,3rd,4thmetatarsal.

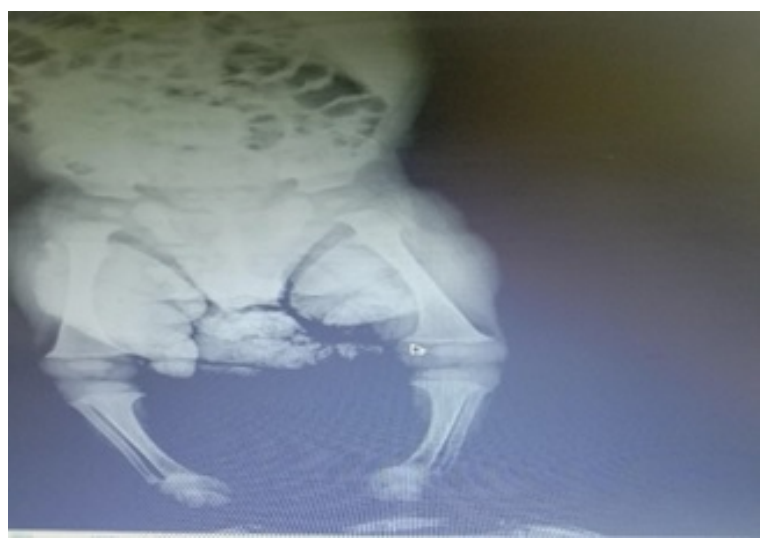

Figure 3. Metaphyseal fracture at right distal femur.

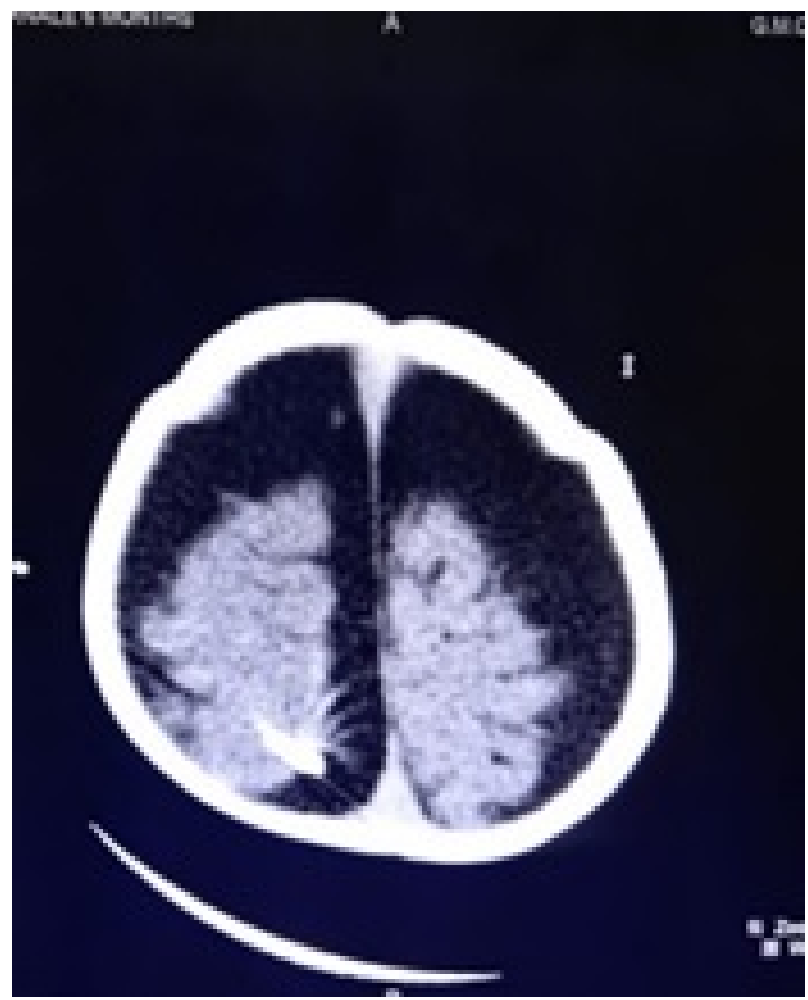




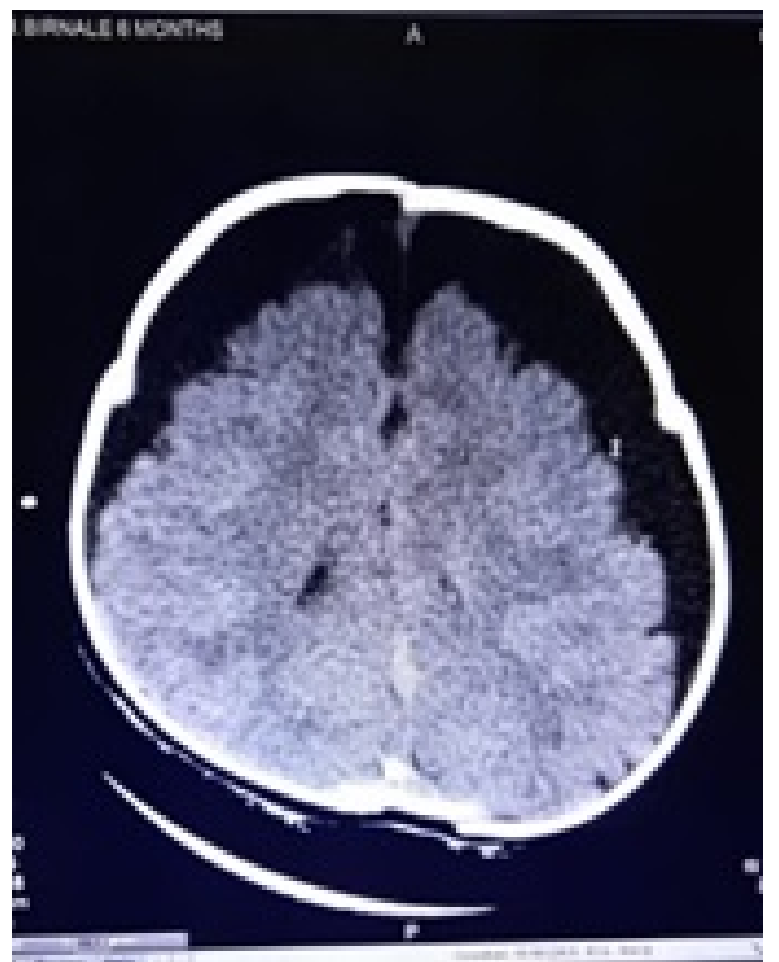

Figure 4. Computerized tomography shows Subdural hygroma with bilateral frontoparietal lobe convexities.

\section{Discussion}

The term child abuse refers to an act or failure to act that violates the right of the child and endangers his or her optimum health, survival or development [6]. A recent WHO estimate shows that 40 million children in the world, aged 0-14 years are abused and neglected, these children require both health and social care. [7]. Cheah et al studied 369 cases of pediatric physical abuse and reported intracranial haemorrhages in $11.4 \%$ of study subjects. $90 \%$ of cases were 2-year-old or less. SDH is the commonest type of bleeding with skull fractures present in only 9 cases. [7]. Computerized tomography Image findings, which co-relate well with intentional trauma to the head are convexity subdural hematoma, inter-hemispheric subdural hematoma, nonhemic subdural fluid (hygroma) and absence of skull fractures. [8]. Some of the risk factors for abuse are a child with mental or physical disabilities, low birth weight, unplanned pregnancy, gender, poverty, unemployment, social isolation, mental health issues of parents. Voluntary inferred injuries have so characteristic location and radiographic pattern that lesions can be classified as of high, moderate or low specificity for child abuse.
According to this classification the lesions with the highest specificity for abuse are rib fractures and classical metaphyseal lesions. Regarding the classical metaphyseal lesions, they are highly specific in children in their first year of life. The accepted mechanism for this type of fracture is the violent shaking of a young child, causing a whiplash-type injury at the level of the zone of provisional calcification.

They have never been described in a patient with OI. [9]. Child abuse should be suspected under the following circumstances-injury to a young infant, patterned injuries, multiple injuries at different stages of healing and unexplained serious injuries. The patient required medical treatment, emotional support, proper counselling and protection; we need to take steps to improve socioeconomic conditions to fight against this burning issue [10].

In a meta-analysis of 21 studies, haemorrhages that were subdural, multiple, in the convexity, interhemispheric, or the posterior fossa were significantly associated with Abusive head trauma (AHT). In addition, hypoxic-ischemic injury and cerebral oedema were significantly associated with AHT. In contrast, epidural hematoma, scalp swelling, and isolated skull fracture were significantly associated with nonabusive head trauma. [11].

Nonaccidental trauma is the most common cause of subdural hematoma in children less than 2 years of age.

Lesson Learnt:

01. Children with Subdural Hygroma have classical neuroimaging features s/o abusive etiology.

02. Multiple fractures at Metaphysis with callus formation suspect child abuse.

03. Multidisciplinary approach \& reporting cases are important to living children in a healthy environment.

\section{Conclusion}

The NCPCR and the Indian Academy of Paediatricians (IAP) have recently taken the initiative to educate paediatricians about child abuse and formulate policies on reporting. The guidelines mandate that paediatricians coming across cases of child abuse should report to police, nongovernmental organisations (NGOs) or help-lines. If they fail to do so, they can be punished for up to two years imprisonment. 
Paediatricians have woken up to the reality of child abuse and are working towards remedial measures but the rest of the medical fraternity is yet to wake up to the fact that a big proportion of children in India are being battered and most go unnoticed and unreported. [1].

As we know there are underreporting of cases of child abuse under $5 y r$ in Rural area, due to lack of suspicion and Infant couldn't able to narrate about abuse, the medical and nursing fraternity must improve their level of awareness towards the problem of child battering, be better equipped to identify them and be more knowledgeable to deal with the circumstance so that the child does not go back to the same environment or suffer further battery.

This case is Special because a 5-month Male infant was subjected to abuse due to a psychological problem in a Family Member, suspicion was lacking as males are unlikely to undergo gender-biased in India and Early age of presentation.

\section{Acknowledgements}

We acknowledge this to Dr Shivprasad Mundada, Head of the Department of Paediatrics, Dr. Atish Komwad, Radiologist and Dr Pushkraj Birajdar Neurosurgeon of VDGIMS LATUR.

\section{Reference}

01. Subba S H, Pant S, Senthilkumaran S, Menezes $\mathrm{R}$ G. Battered child syndrome: Is India in dire straits?. Egyptian Journal of forensic sciences. 1;34(2011):111-113. [Crossref][PubMed][Google Scholar]

02. Ramsey, Jerry A, and Byron J Lawler. "The Battered Child Syndrome". Pepperdine Law Review. 1;3(1974):3. [Crossref][PubMed][Google Scholar]

03. Swischuk, Leonard E, and Siddharth P Jadhav. "Battered Child Syndrome/Non-accidental Trauma", Emergency Musculoskeletal Imaging in Children. Springer, New York, NY. 2014; 217-229. [Crossref] [PubMed][Google Scholar]

04. Nandy A. Principles of forensic medicine. New Central Book Agency (P) Ltd, Calcutta. 2010;p-56974. [Crossref][PubMed][Google Scholar]

05. Kumar, Raj. "Chronic subdural fluid collection in children". JK Science. 7(2005):1-3. [Crossref] [PubMed][Google Scholar]
06. Nair MK. Child abuse. Indian paediatric. 2004;41(4)319-20. Available at [Article][Crossref] [PubMed][Google Scholar]

07. Cheah IG, Kasim MS, Shafie HM, Khoo TH. Intracranial haemorrhage and child abuse. Ann Trop Paediatr. 1994;14(4):325-8. doi: 10.1080/02724936.1994.11747737 [Crossref] [PubMed][Google Scholar]

08. Wells RG, Vetter C, Laud P. Intracranial hemorrhage in children younger than 3 years: prediction of intent. Arch Pediatr Adolesc Med. 2002 Mar;156(3):252-7.

doi:

10.1001/archpedi.156.3.252 [Crossref][PubMed]

[Google Scholar]

09. D'Eufemia P, Palombaro M, Lodato V, Zambrano A, Celli M, Persiani $P$, et al. Child abuse and osteogenesis imperfecta: how can they be still misdiagnosed? A case report. Clin Cases Miner Bone Metab. 2012 Sep;9(3):195-7. [Crossref][PubMed] [Google Scholar]

10. Pezeshki A, Rahmani F, Ebrahimi Bakhtavar $H$, Fekri S. Battered Child Syndrome; a Case Study. Emerg (Tehran). 2015 Spring;3(2):81-2. [Crossref] [PubMed][Google Scholar]

11. Hsieh $\mathrm{KL}$, Zimmerman RA, Kao HW, Chen $\mathrm{CY}$. Revisiting neuroimaging of abusive head trauma in infants and young children. AJR Am J Roentgenol. 2015 May;204(5):944-52. doi: 10.2214/AJR.14.13228 [Crossref][PubMed][Google Scholar] 